\title{
Impacts of Artisanal mining on Some Heavy Metals Concentration in Surface Water in Kutcheri, Zamfara State, North-West Nigeria
}

\author{
Rasheed A. Ishola ${ }^{1}$, Abdulgafar K. Amuda ${ }^{2}$ \\ ${ }^{1}$ Department of Chemistry, Federal University Lokoja, Lokoja, Kogi State, Nigeria \\ ${ }^{2}$ Department of Geology, Ahmadu Bello University, Zaria, Kaduna State, Nigeria
}

\begin{abstract}
This research assesses the concentration of $\mathrm{Zn}, \mathrm{Ag}, \mathrm{Hg}, \mathrm{Pb}$ and $\mathrm{Cu}$ in surface water Kutcheri's River Yankuzau and other streams coordinates range between longitude $11^{\circ} 48^{\prime} \mathrm{N}$ to $11^{\circ} 53{ }^{\prime} \mathrm{N}$ and latitude $7^{\circ} 00^{\prime}$ to $7^{\circ} 05^{\prime} \mathrm{E}$ using Atomic Absorption Spectrophotometre (AAS). Artisanal mining has become prominent in these areas. It's become imperative to analyze these metal concentrations because they are associated with gold mineralization. Apart from polluting the water by artisanal miners, heavy metals are released into the surface water which most villager drink without pretreatment.
\end{abstract}

Keywords: heavy metals; Kutcheri’s River; Zamfara State, Nigeria

\section{INTRODUCTION}

The interest in the environmental levels of heavy metals is a global one because of the potential hazards of these elements to the health of animals, humans and plants when they exist at elevated levels (Oyekunle et al., 2012). The escalating environmental contamination by heavy metals is of growing concern in Nigeria and Worldwide (Ezemonye, et al 2005). A wide range of contaminants are continuously introduced into the aquatic environment mainly due to increased industrialization, technological development, growing human population, oil exploration and exploitation, agricultural and domestic wastes run-off (Lima et al., 2008). In his quest to satisfy his needs and aspirations for better living conditions through resource exploitation man has created an increasing number of environmental problems. He exploit nature, and in so doing distort the natural equilibrium which in turn have been proved to be harmful to animals and man himself. Following the exploitation of land and water resources, various forms of pollution contributes to the degradation of the environmental quality. (Udiba U., et al 2012) Water is indispensable. It is not only essential for the survival of man but also for other living organism (Asuquo, et al 1998). It is an essential nutrient that is involved in every function of the human body and constitutes about two-third of the human body. The importance of water in our daily life makes it imperative that thorough microbiological and physio-chemical examinations be conducted on water. (Pavendan, et al 2011,) Water for human consumption must be free from microorganisms and chemical substances in concentrations large enough to cause environmental imbalance and disease. The World 
Health Organization (WHO) estimated in 1996 that every eight seconds a child dies from a water-related disease and that each year more than five million people died from illnesses linked to unsafe drinking water or inadequate sanitation (Shivaraju H.P.2012). The environmental impacts of gold mining are particularly severe because of the chemical processes often used to extract gold. At the present time, most of local communities in Zamfara state,Nigeria. used Mercury amalgamation method in extracting gold.

This process is particularly degrade and pollute the environment, infringes the principle of sustainable development, consumes large water and creates a morass of hazardous waste. Considering all of these consequences, the need to assess the quality of surface water in terms of their metallic load in all the gold mining areas of Zamfara state becomes imperative since water from these sources is being used for drinking, domestic irrigation and livestock activities by people living in the catchment areas. In view of the health implications that cut across the food strata. Several years of illegal and small scale gold mining activities in Zamfara state are a potential source of environmental pollution. However, knowledge of metals concentration in surface water in these gold mining communities is not available or fairly limited. The present study is planned to address these issues by taking into consideration, the assessment of concentration levels of $\mathrm{Pb}$ and other heavy metals known to be associated with gold ore through the following:

a) To quantify the contents of $\mathrm{Pb}$ and other heavy metals ( $\mathrm{Hg}, \mathrm{Ag}, \mathrm{Cu}$, and $\mathrm{Zn}$ ), in surface water in Kutcheri environs artisanal gold mining and processing site using Atomic Absorption Spectroscopy (AAS).

b) To provide a data on the concentration $\mathrm{Pb}$ and other heavy metals associated with the study area.

c) To suggest remedial measures for various types of contaminations, if found in the study area.

This study will give a direction for rapid and coordinated intervention by State and Federal authorities, non-governmental organization as well as the international community.

\section{1. Gold Mining Process}

Gold as a precious metal found in small quantities, it's mining operations tend to cover wide areas, thus can inflict environmental damage over a geographically wide area. The mining process sometimes is complex and results in the release of highly toxic pollutants. Gold mining tends to huge negative impacts on the environment from digging out a huge pit to disposing of the left over chemicals and tailings (Sabah, A. A. et al 2012). Heavy metals associated with gold mining are of particular interest for a number of reasons:

(i) They show a tendency to accumulate in sediments and soils and have a long persistence time because they are not biodegradable.

(ii) They are ubiquitous in sediments and soils arising from both natural and anthropogenic sources with pathways including inheritance from the parent rocks, application of water as well as local and long-range atmospheric and fluvial deposition of emissions from dust and mining. These metals can then enter the food chain via uptake by plants and animals including man. During the processing of the ores for the gold, poisonous substances such as oxides and sulphides of heavy metal pollutants are released into the environment. Other heavy metals associated with the gold, such as arsenic (As), cadmium $(\mathrm{Cd})$, lead $(\mathrm{Pb})$, zinc $(\mathrm{Zn})$ and copper $(\mathrm{Cu})$ may be freed to enter streams. Mercury $(\mathrm{Hg})$ may also enter streams if miners use it to recover fine particles of gold. The geochemical investigation of waters and 
sediments is of major importance in the study of aquatic systems, as they provide information about the heavy metals dissolved. The sediment of any water body contains a historical record of the natural and anthropogenic fluxes of heavy metals received into the water basin (Boamponsem, L. K. et al 2010,).

\section{2. Use of Water in Gold Mining}

Gold mining operations utilize large volumes of water, diverting local water resources away from other uses. Disposal methods for Wastewater by artisanal miners are highly variable and depend to a large degree on local regulations. In many developing countries, Wastewater containing toxic chemicals is discharged directly into the water supply. Because mining lobbies and environmental groups are constantly advocating on opposite sides of the issue, mining waste and water quality regulations also vary significantly over time. Even in areas with relatively strict waste management standards, significant amounts of toxic. chemicals and heavy metals contaminate nearby water sources. Strip mining and mountaintop removal can destroy entire watersheds and result in sedimentation of waterways. Many mining activities also use large volumes of water to process ore (Kendall O. (2013).).

\section{2. 1. The Environmental Impacts on Water Sources Near Mine Dumps.}

Mining processes result in large amounts of toxic waste, which need to be disposed of or stored. In developing counties, due to lax regulations, large amounts of mine tailings are simply sent into rivers, resulting in considerable ecological damage and contamination of human water supplies. Older abandoned mines often have exposed tailing piles that are poorly contained. Particulate mine tailings can be carried by wind to contaminate broad areas, including waterways. Modern mines utilize a variety of containment methods, including pond storage, which minimize but do not completely eliminate the spread of toxins into water sources. While mining regulations have become stricter, mining technologies result in higher productivity, leading to larger amounts of mining waste. Mines invariably contaminate surface and ground water, even when mines have containment systems in place. Chemicals such as sulfur, arsenic, mercury and cyanide seep into ground water during mining operations, or get washed away by rainwater, collecting in rivers, lakes and aquifers. Many abandoned mines leave toxic waste dumps that leach chemicals and heavy metals for decades, much of which ends up in water sources. Acid mine drainage frequently occurs with coal mines, polluting waterways and destroying terrestrial habitats in large areas surrounding the mines (Kendall O. 2013).

\section{2. 2. Water Pollution}

Once ore is gathered from mines, it can be extracted by using different methods. One such method, called leaching, is a low-cost method of removing ore from waste. During the process, workers pile low-grade gold ore into an outdoor heap and put a cyanide or mercury solution on it. The cyanide/mercury then dissolves the gold, which it runs down a slope into reservoirs before it is collected. In some countries, environmental laws require that the slopes and collection vats are impenetrable so that poisons cannot be released into the ground. However, lack of protections in other countries mean that the poisons are often leaked into the soil. These materials then make their way into local water supplies, lakes, rivers and streams. Drainage of this type raises acid levels in lakes which are harmful to both animals and people. Additionally, some mines intentionally dispose toxic wastes into oceans, lakes and rivers, while others place wastes or tailings in dammed reservoirs that can occasionally 
burst and flood areas, releasing mercury and other heavy metals into the water supply. Pollution From mines can cause drinking water contamination and high levels of mercury or their heavy metals in fish (Kendall O., 2013).

\section{3. Negative Effects of Gold Mining}

Gold is a precious metal used around the world in jewellery, electronics and even dentistry. Extraction of gold requires mining for it beneath the Earth's surface. Mining for gold has some negative effects, including erosion, the use of mercury, loss of biodiversity, and disruption of indigenous communities (Kendall O., 2011).

\subsection{Erosion}

Erosion is when solid deposits are weathered over a period of time and moved from their natural spot to a new destination. Erosion occurs naturally in the wild, but can also occur as a negative effect of gold mining. Excessive amounts of gold mining can wash away soil into nearby rivers, as well as strip an area of soil altogether. Serious erosion can also strip an area of its ability to support Agriculture (Kendall O., 2011).

\subsection{Mercury}

The chemical mercury is used in the extraction of gold from ore. It is very toxic to humans and animals. When the chemical enters the body, it suppresses the central nervous system causing respiratory failure and death. The mercury used in gold mining can get into the soil, and through the process of erosion can make its way into lakes and streams. This in turn can pollute local water supplies (Kendall O., 2011).

\section{3. 3. Loss of Biodiversity}

In the gold mining process, land must be cleared for mining. Clear-cutting trees disrupts local ecosystems, causing animals to flee the area or perish. Also, when the chemicals used in gold mining make their way into the soil and the water, they disrupt the local wildlife by poisoning their sources of food and water. It is not unusual in gold mining for toxic chemicals to be simply dumped into local ponds In many remote parts of the world, indigenous communities still exist and gold mining may disrupt their lives. Large gold mining companies will often secure land deals from the local governments, and in this process eject, often violently, the local indigenous population. Governments in these regions have been known to kill indigenous people for refusing to leave areas that have been sold to gold mining companies (Kendall O., 2011).

\section{4. Macro-nutrients}

These metals are required by body in good quantities for proper metabolism and functioning of body organs (Lokeshappa B. et al., 2012). They are referred to as the trace elements. These include iron, zinc, calcium, magnesium, sodium, potassium, copper, and manganese. These elements, or their compounds, are commonly found naturally in foodstuffs, in fruits and vegetables, and in commercially available multivitamin products (Galadima, A. et al., 2012). 


\section{4. 1. Iron (Fe)}

The total amount of iron in the human body is approximately $4 \mathrm{~g}$, of which $70 \%$ is present in red blood colouring agents. Iron is a dietary requirement for humans, just as it is for many other organisms. Men require approximately $7 \mathrm{mg}$ iron on a daily basis, whereas women require $11 \mathrm{mg}$. The difference is determined by menstrual cycles. When people feed, normally these amounts can be obtained rapidly. The body absorbs approximately $25 \%$ of all iron present in food. When someone is iron deficit feed iron intake may be increased by means of vitamin $\mathrm{C}$ tablets, because this vitamin reduces tertiary iron to binary iron. Phosphates and phytates decrease the amount of binary iron. In food iron is present as binary iron bound to haemoglobin and myoglobin, or as tertiary iron. The body may particularly absorb the binary form of iron. When iron exceeds the required amount, it is stored in the liver. The bone marrow contains high amounts of iron, because it produces haemoglobin. Iron deficits lead to anaemia, causing tiredness, headaches and loss of concentration. The immune system is also affected. In young children this negatively affects mental development, leads to irritability, and causes concentration disorder. Young children, pregnant women and women in their period are often treated with iron (II) salts upon iron deficits. When high concentrations of iron are absorbed, for example by haemochromatose patients, iron is stored in the pancreas, the liver, the spleen and the heart. This may damage these vital organs Healthy people are generally not affected by iron overdose, which is also generally rare. It may occur when one drinks water with iron concentrations over $200 \mathrm{ppm}$. (Lenntech B. V., 2013).

\section{4. 2. Copper $(\mathrm{Cu})$}

Copper is an essential substance to human life, but its critical doses can cause anaemia, acne, adrenal hyperactivity and insufficiency, allergies, hair loss, arthritis, autism, cancer, depression, elevated cholesterol, depression, diabetes, dyslexia, failure to thrive, fatigue, fears, fractures of the bones, headaches, heart attacks, hyperactivity, hypertension, infections, inflammation, kidney and liver Dysfunction, panic attacks, strokes, tooth decay and vitamin $\mathrm{C}$ and other vitamin deficiencies (Lokeshappa B et al., 2012). Copper enters the air, mainly through release during the combustion of fossil fuels. Copper in air will remain there for an eminent period of time, before it settles when it starts to rain. It will then end up mainly in soils. As a result soils may also contain large quantities of copper, after copper from the air has settled. Copper can be released into the environment by both natural sources and human activities. Examples of natural sources are wind-blown dust, decaying vegetation, forest fires and sea spray. A few examples of human activities that contribute to copper release are mining, metal production, wood production and phosphate fertilizer production. Because copper is released both naturally and through human activity it is very widespread in the environment. Copper is often found near mines, industrial settings, landfills and waste disposals. Most copper compounds will settle and be bound to either water sediment or soil particles. Soluble copper compounds form the largest threat to human health. Usually watersoluble copper compounds occur in the environment after release through application in agriculture. Copper can be found in many kinds of food, in drinking water and in air. Because of that we absorb eminent quantities of copper each day by eating, drinking and breathing Lenntech B. V. (2013). 


\section{5. Toxic metals}

Lead, cadmium, mercury, arsenic and their inorganic compounds, are toxic to human health as well as the environment.( Lokeshappa B.et al.,2012). The toxicity details of some of the metal caused human disorders are described below:

\section{5. 1. Lead (Pb)}

Lead is a naturally occurring bluish-gray metal found in small amounts in the earth's crust. Lead can be found in all parts of our environment. Much of it comes from human activities including burning fossil fuels, mining, and manufacturing. Lead has many different uses. It is used in the production of batteries, ammunition, metal products (solder and pipes), and devices to shield X-rays [7]. The effects of lead are the same whether it enters the body through breathing or swallowing. Lead can affect almost every organ and system in your body. The main target for lead toxicity is the nervous system, both in adults and children. Long-term exposure of adults can result in decreased performance in some tests that measure functions of the nervous system. It may also cause weakness in fingers, wrists, or ankles. Lead exposure also causes small increases in blood pressure, particularly in middle-aged and older people and can cause anemia. Exposure to high lead levels can severely damage the brain and kidneys in adults or children and ultimately cause death. In pregnant women,high levels of exposure to lead may cause miscarriage. High level exposure in men can damage the organs responsible for sperm production (UNEP/OCHA (2010).).

Children are more vulnerable to lead poisoning than adults. A child who swallows large amounts of lead may develop blood anemia, severe stomachache, muscle weakness, and brain damage. If a child swallows smaller amounts of lead, much less severe effects on blood and brain function may occur. Even at much lower levels of exposure, lead can affect a child's mental and physical growth. Exposure to lead is more dangerous for young and unborn children. Unborn children can be exposed to lead through their mothers. Harmful effects include premature births, smaller babies, decreased mental ability in the, learning difficulties, and reduced growth in young children. These effects are more common if the mother or baby was exposed to high levels of lead. Some of these effects may persist beyond childhood. It is important to note that even children who seem healthy can have high levels of lead in their bodies (UNEP/OCHA (2010))..Lead poisoning is most commonly caused by ingestion and inhalation of lead and lead compounds. Lead causes damage to multiple body systems, and the nervous system isparticularly vulnerable, especially in young children. Chronic lead poisoning occurs when small amounts of lead are taken in over a longer period. The Centers for Disease Control and Prevention (CDC) defines childhood lead poisoning as a wholeblood lead concentration equal to or greater than 10 micrograms/dL. Acute lead poisoning, while less common, shows up more quickly and can be fatal, when a relatively large amount of lead is taken into the body over a short period of time. Children constitute the vast majority of such cases. Symptoms can include severe abdominal pain, diarrhea, nausea and vomiting, weakness of the limbs, seizures, and coma (UNEP/OCHA (2010).

\section{5. 2. Mercury (Hg)}

Mercury is a naturally occurring metal which has several forms. The most common one, methyl mercury, is produced mainly by microscopic organisms in the water and soil. More mercury in the environment can increase the amounts of methyl mercury that these small organisms make. Metallic mercury is used to produce chlorine gas and caustic soda, and is also used in thermometers, dental Fillings, and batteries. Mercury salts are sometimes 
used in skin lightening creams and as antiseptic creams and ointments (UNEP/OCHA (2010).. Exposure to mercury occurs from breathing contaminated air, ingesting contaminated water and food, and having dental and medical treatments. Mercury, at high levels, may damage the brain, kidneys, and developing fetus. Inorganic mercury (metallic mercury and inorganic mercury compounds) enters the air from mining ore deposits, burning coal and waste, and from manufacturing plants. It enters the water or soil from natural deposits, disposal of wastes, and volcanic activity. The nervous system is very sensitive to all forms of mercury. Methyl mercury and metallic mercury vapors are more harmful than other forms, because more mercury in these forms reaches the brain (UNEP/OCHA (2010). Exposure to high levels of metallic, inorganic, or organic mercury can permanently damage the brain, kidneys, and developing fetus. Effects on brain functioning may result in irritability, shyness, tremors, changes in vision or hearing, and memory problems. Short-term exposure to high levels of metallic mercury vapors may cause effects including lung damage, nausea, vomiting, diarrhea, increases in blood pressure or heart rate, skin rashes, and eye irritation. Very young children are more sensitive to mercury than adults (UNEP/OCHA (2010).

\section{MATERIALS AND METHODS}

\section{1. Locations of the research}

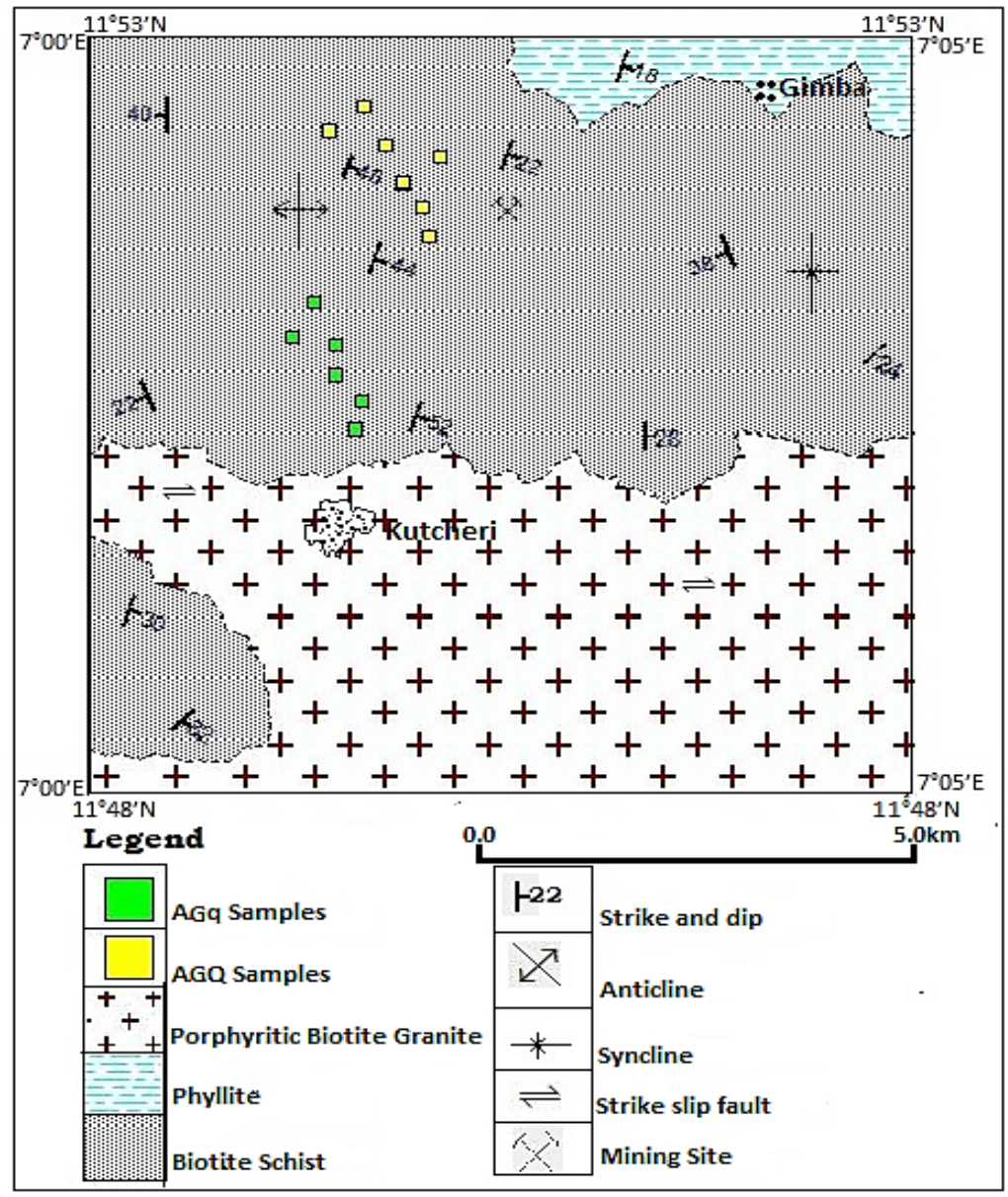

Geological map of area around Kutcheri. 
The study areas are within The coordinates range between longitude $11^{\circ} 48^{\prime} \mathrm{N}$ to $11^{\circ} 53^{\prime} \mathrm{N}$ and latitude $7^{\circ} 00^{\prime}$ to $7^{\circ} 05^{\prime} \mathrm{E}$ Kutcheri, Zamfara State - Nigeria.

\section{2. Apparatus and Reagents}

All the chemicals and reagents used in this study were of analytical grades, and the glass wares used were cleaned, rinsed with distilled water and air dried. They include: Weighing balance (Mettle P.M. 16k, Gallen Kamp UK), Filter Paper (What man $(12 \mathrm{~cm})$, What Man LTD England), while oven, beaker, volumetric flask and digestion flask are pyrex brand from Kort-Koll, Germany. The analyses of the metals were carried out using Shimadzu AA 7000 atomic absorption spectrophotometer (BUCK AAS 210 VGP . Spectrum, USA) attached to graphite atomizer and a Printer.

\section{3. Methods of Preparation of Reagents}

The solvents used were prepared as described below:

(a) $5 \%$ Nitric acid $\left(\mathrm{HNO}_{3}\right): 5 \mathrm{~mL}$ concentrated $\mathrm{HNO}_{3}$ was pipette into a $100 \mathrm{~cm}^{3}$ volumetric flask and made up to mark with distilled water.

(b) $50 \%$ Nitric acid $\left(\mathrm{HNO}_{3}\right): 50 \mathrm{~mL}$ concentrated $\mathrm{HNO}_{3}$ was pipette into a $100 \mathrm{~cm}^{3}$ volumetric flask and made up to mark with distilled water.

(c) $1: 1(\mathrm{v} / \mathrm{v})$ Nitric acid $\left(\mathrm{HNO}_{3}\right) /$ Distilled water: $125 \mathrm{~cm}^{3}$ of concentrated $\mathrm{HNO}_{3}$ was measured into a $250 \mathrm{~cm}^{3}$ volumetric flask and made up to mark with distilled water.

\section{4. Sample Collection and Treatment}

Sample containers were thoroughly washed with detergent, rinsed with water followed by distilled water before soaking in $5 \% \mathrm{HNO}_{3}$ for about 24 hours. Surface water samples were collected from gold processing site in Kutcheri, Zamfara State.

\section{5. Treatment of Samples for AAS Analysis}

\section{5. 1. Surface water Sample}

The surface water samples $\left(100 \mathrm{~cm}^{3}\right)$ was filtered using cellulose nitrate filter papers $(0.45 \mu \mathrm{m}$ pore size $)$, acidified with $50 \% \mathrm{HNO}_{3}$ acid solution to achieve a $\mathrm{pH}$ of 2.0. The addition of acid to water sample is to keep the metal ions in the dissolved state, as well as to prevent microbial activities.

The samples were then kept in a refrigerator until they were dispatched to the AAS analysis Eletta B. E. (2012).

\section{RESULT AND DISCUSSION}

The mean concentration of heavy metal analyzed is presented in Table 1 . For $\mathrm{Zn}$, it has an average concentration of $3.18 \pm 2.305$ in the surface water when compared with World Health Organization guidelines for portable drinking water the value is almost $1 / 2$ the acceptable limit (5.00) AG5 has the highest concentration.

For $\mathrm{Pb}$ it has an average concentration of $0.014 \pm 0.004$ in in the surface water when compared with World Health Organization guidelines for portable water it is slightly higher 
than the acceptable limit for drinking water (0.01 ppm). AG5 has the highest $\mathrm{Pb}$ concentration.

For $\mathrm{Hg}$, it has an average concentration of $0.006 \pm 0.01$ in the surface water; comparing the results with World Health Organization guidelines for portable drinking water the value is two times higher than the acceptable limit of $0.01 \mathrm{ppm}$. these value is lower than $0.009 \mathrm{ppm}$ reported by Cobbina et al., (2013) in water sources of small scale mining area of Datuku I the Talensi-Nabodan district Ghana Zone AG3 \& AG5 having the highest concentration. For $\mathrm{Cu}$, the mean concentration of $1.028 \pm 0.887$ in surface water when.

Its comparison with World Health Organization guidelines for portable drinking water i.e. $2.00 \mathrm{ppm}$ the value obtained for surface water is lower.

Table 1. Concentration of analytes around Kutcheri and statistical relations.

\begin{tabular}{|c|c|c|c|c|c|}
\hline \multirow{2}{*}{ Location } & \multicolumn{5}{|c|}{ Analyte (ppm) } \\
\hline Kutcheri & $\mathrm{Zn}$ & $\mathrm{Ag}$ & $\mathrm{Hg}$ & $\mathrm{Pb}$ & $\mathrm{Cu}$ \\
\hline $\mathrm{AG} 1$ & 1.2 & 0.003 & 0.00 & 0.013 & 1.01 \\
\hline AG2 & 3.6 & 0.006 & 0.00 & 0.011 & 0.00 \\
\hline AG3 & 3.2 & 0.004 & 0.002 & 0.010 & 1.24 \\
\hline AG4 & 4.8 & 0.004 & 0.00 & 0.017 & 2.10 \\
\hline AG5 & 6.3 & 0.006 & 0.002 & 0.023 & 1.82 \\
\hline AG6 & 0.00 & 0.002 & 0.00 & 0.011 & 0.00 \\
\hline Mean & 3.18 & 0.004 & 0.006 & 0.014 & 1.028 \\
\hline $\begin{array}{c}\text { Standard } \\
\text { Deviation }\end{array}$ & 2.305 & 0.002 & 0.001 & 0.004 & 0.89 \\
\hline Variance & 5.31 & 2.57 & 1.01 & 2.50 & 0.655 \\
\hline W.H.O LIMIT & 5 & NA & 0.001 & 0.01 & 0.05 \\
\hline NSWQ & 3 & NA & 0.001 & 0.01 & 1 \\
\hline
\end{tabular}

Key: W.H.O World Health Organization

NSWQ-Nigerian Standard for Water Quality

Results were presented as mean \pm standard deviation of triplicate analysis.

The distribution of the metals for each sites longitude $11^{\circ} 48^{\prime} \mathrm{N}$ to $11^{\circ} 53^{\prime} \mathrm{N}$ and latitude $7^{\circ} 00^{\prime}$ to $7^{\circ} 05^{\prime} \mathrm{E}$ are depicted below. 

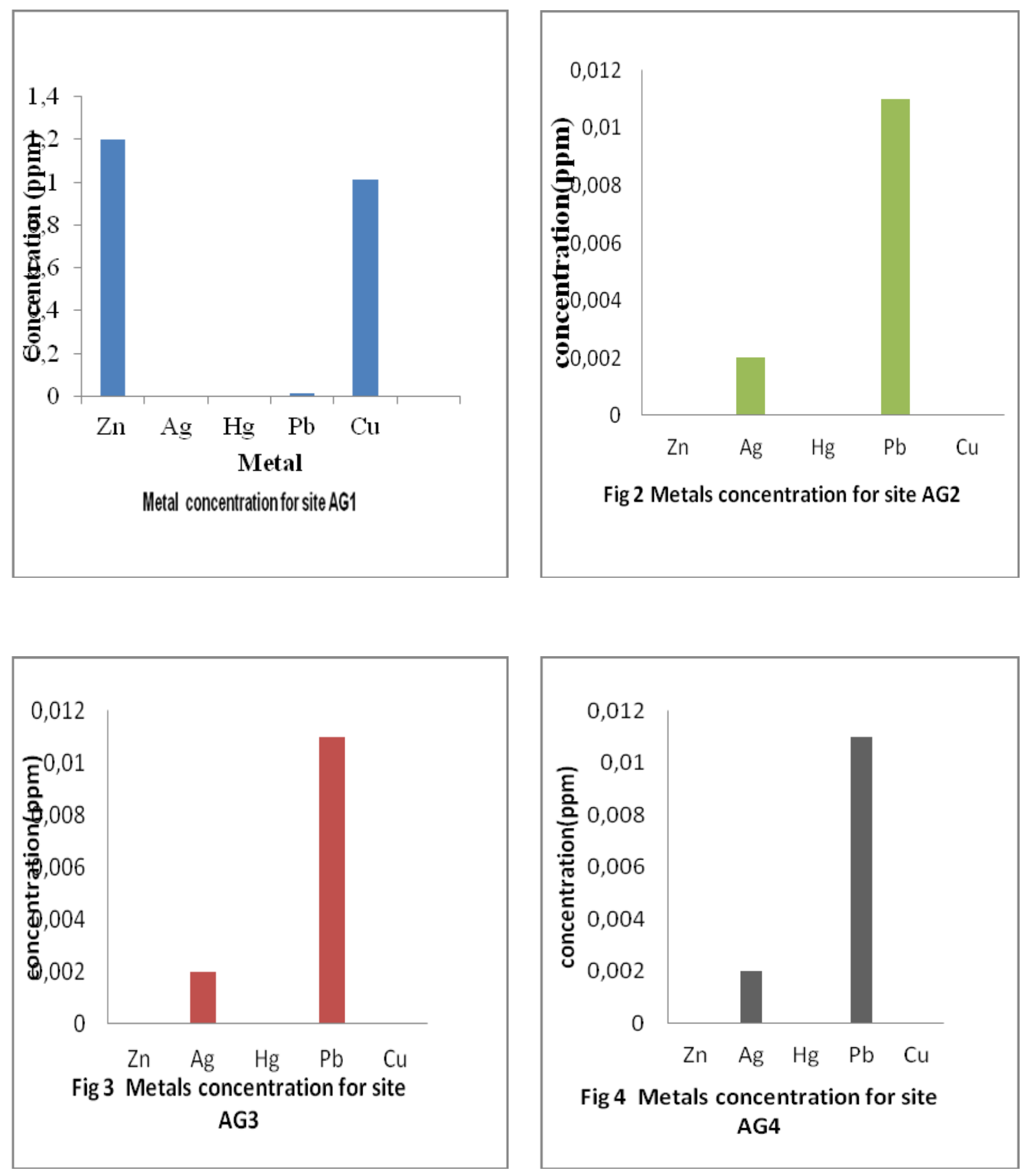

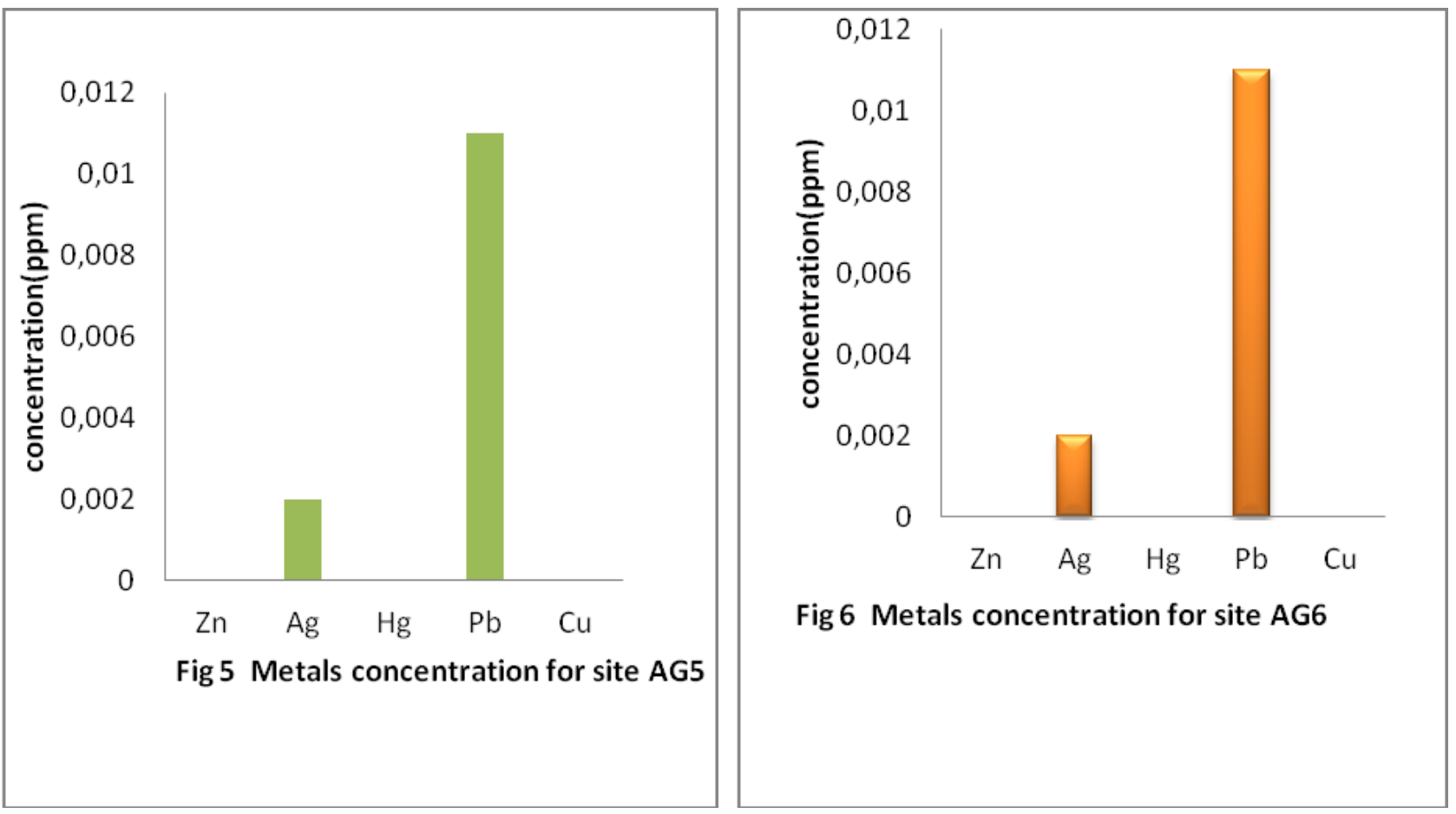

The mean concentration of these metals is depicted in Fig. 7 below.

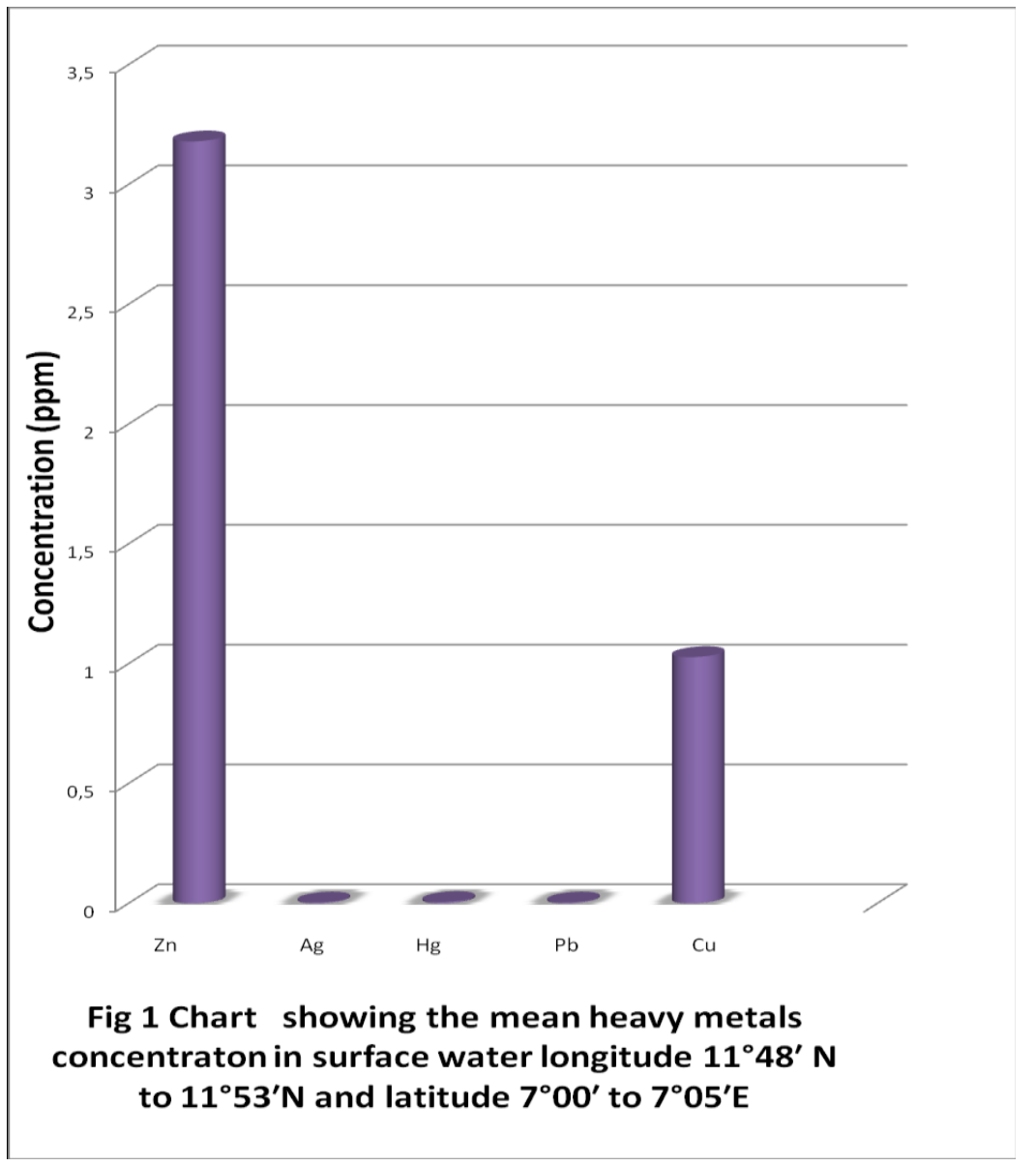




\section{CONCLUSION AND RECOMMENDATION}

\section{1. Conclusion}

The results of the study shows that the presence of these metals at minimal level in all the six locations. When compared with World Health Organization limits. Direct and indirect discharge of ore waste and other mining processes have direct effect on surface water. This research may serve as a reference for studying the trends of artisanal mining in these areas $\left\{11^{\circ} 48^{\prime} \mathrm{N}\right.$ to $11^{\circ} 53^{\prime} \mathrm{N}$ and latitude $7^{\circ} 00^{\prime}$ to $\left.7^{\circ} 05^{\prime} \mathrm{E}\right\}$. It is recommended that there should be mining policy to prevent water contamination through artisanal mining. Since the level of the analyzed metals is not alarmingly high steps must be taken by law environmental protection and mining regulatory agents to ensure such environment is not degraded further.

\section{2. Recommendations}

In view of the results obtained, the following recommendations are hereby suggested:-

1. The adoption of National and International accepted safe mining practices.

2. Educating local miners on the dangers of using ore grinders for grains to be consumed.

3. Restricting children from entering mining sites.

4. There should be provision of alternative means of livelihood as artisanal mining have replaced farming and livestock raising in this communities.

5. Provision of portable drinking water. This would stop inhabitants from drinking contaminated waters.

\section{References}

[1] Asuquo F. E., Global journal of Pure and Applied Science 5 (1999) 595-600.

[2] Boamponsem L. K., Adam J. I., Dampare S. B., E. Owusu-Ansah, Addae G., J. Chem. Pharm. Res. 2(3) (2010) 504-527.

[3] Cobbina S. J., Myilla M., Michael K., International journal of scientific \& the tific \& technology research 2(1) (2013) 96-100.

[4] Ezemonye L. I. N., Enuneku A., Journal of Aquatic Science 20(1) (2005) 33-36.

[5] Eletta B. E., Journal of Nuclear and Particle 2(4) (2012) 87-90.

[6] Kendall O. (2013). Types of Pollution Generated by Gold Mining: ehow health. Demand Media, Inc.

http://www.ehow.com/list_6811335_types-pollutiongenerated-gold mining.html\#ixzz21GEWQHEt retrieve on 23/11/2013.

[7] Lima D., Santos M. M., Ferreira A. M., Micaelo C. Reis-Henriques, Environment International 3 (2008) 94-101.

[8] Lokeshappa B., Kandarp S., Vivek T., Anil K. D., Food and Public Health 2(1) (2012) 24-29.

[9] Oyekunle J.A.O., Adekunle, A.S., Ogunfowokan, A.S., Akanni M.S., Coker O.S., African Journal of Environmental Science and Technology 6 (12) (2012) 458-463. 
[10] Pavendan P., S. Anbu Selvan, C. Sebastian rajasekaran, European Journal of Experimental Biology 1(1) (2011) 183-189.

[11] Shivaraju H. P., Int. J. Res. Chem. Environ. 2(1) (2012) 44-53.

[12] Sabah A. A., Fouzul A. M., European Journal of Engineering 2(2) (2012) 304-313.

[13] Udiba U. U. et al., Journal of Basic and Applied Scientific Research 2(2) (2012) 1658-1666.

[15] UNEP/OCHA (2010). Lead Pollution and Poisoning Crisis Environmental Emergency Response Mission, Zamfara State, Nigeria. Published in Switzerland, by the Joint UNEP/OCHA Environment Unit

[16] WHO (2008). World Health Organisation, Guidelines for drinking water quality, World Health Organization, Geneva.

[17] Omprakash Sahu, International Letters of Natural Sciences 7 (2014) 35-43.

[18] Omprakash Sahu, International Letters of Natural Sciences 8(1) (2014) 1-8.

[19] Ashwani Kumar Dubey, Omprakash Sahu, International Letters of Natural Sciences 11(2) (2014) 121-130.

[20] Debika Bhunia, Subhodeep Sarkar, Kushal Banerjee, Abantika Nandy, Soumendra Nath Talapatra, International Letters of Natural Sciences 14 (2014) 11-20. 